\title{
Cross-type Optical Particle Separation in a Micro-channel
}

Sang Bok Kim, Sang Youl Yoon, Hyung Jin Sung* and Sang Soo Kim*

\author{
Department of Mechanical Engineering \\ Korea Advanced Institute of Science and Technology \\ 373-1, Guseong-dong, Yuseong-gu, Daejeon, 305-701, Korea
}

\section{Contents}

Video S-1: Particles behavior in cross-type optical particle separation in a micro-channel. 
Video S-1: Particles behavior in cross-type optical particle separation in a micro-channel.

Video S-1 shows particles behavior in cross-type optical particle separation in a micro-channel. In the experiments, the flow velocity was $250 \mu \mathrm{m} / \mathrm{s}$, the laser power was $1 \mathrm{~W}$, particle diameter was $5 \mu \mathrm{m}$ and the laser beam radius was $40 \mu \mathrm{m}$. Initially, the particles move downstream with a straight trajectory and then deviate on entering the laser beam. 